\title{
Consideration of cumulative effects in concrete structures at low temperatures impact
}

\author{
Boris Pinus ${ }^{1, *}$ \\ ${ }^{1}$ Irkutsk National Research Technical University, 664074, Lermontova str., 83, Irkutsk, Russia
}

\begin{abstract}
The design of reinforced concrete elements for a determined service life in severe climatic conditions should provide an additional resilience resource in accordance with their serviceability limit state. For its statistical justification, it is proposed to use dynamic models of the change in freezing and thawing cycles (FTC) of reliability index $\beta$, and, as its minimum (at most) permissible value, the value corresponding to the required level of reliability. Statistically representative experimental data of kinetics are presented for FTC of index $\beta$, determined from the change in various controlled parameters of strength and deformability of concrete.
\end{abstract}

\section{Introduction}

Design support of the required level of reliability of reinforced concrete structures operated under extreme conditions is presumably achieved by appropriate calibration of partial coefficients to the normative package of constructive and functional models that take into account the influence of the environment. With reference to the designs of the "northern execution", it is associated with an analysis of the changes in the determining parameters of the resistance, depending on the intensity, frequency, and amplitude of temperature-humidity fluctuations $(T-W)$. The inevitable wear (aging) of structural elements under similar conditions can be considered as a fatigue process with different cumulative effects (structure transformation, fatigue accumulation of deformations, microcracks, etc. [1-4]).

An analytical evaluation of such processes using basic assumptions of the method of limit states and physical patterns of behavior of reinforced concrete elements under cyclic lowtemperature impact predetermine the need for a probable analysis of two transient design situations:

- resistance in the state of freezing to a certain (normative) level;

- resistance in the thawed state after a corresponding number of cycles of $T$ - $W$ impacts.

The instantaneous dynamic models that are realized in this case must establish the relationships between predetermined parameters of the environment, reaction (response) of the structure and the indices of its operational usefulness. These requirements will most closely correspond to functional dependencies containing indicators:

a) included in the normative models of calculated ultimate limit states;

b) sensitive to cyclic climatic impact;

* Corresponding author: pinus@istu.edu 
c) directly or indirectly controlled by acceptable standardized methods.

With this approach, it becomes possible at the design stage to predict the cumulative error failure of construction as the probability of achieving maximum permissible values by one or more controlled parameters.

\section{Materials and methods}

Differential-statistical analysis of normative models of strength and rigidity of reinforced concrete elements in accordance with recommendations of accelerated reliability tests $[5,6]$ found that the above requirements most correspond to indicators of structural properties of concrete, taking into account the patterns of distribution of their random realizations. For their experimental substantiation, purposeful statistically representative tests of prismatic (10 $\times 10 \times 40 \mathrm{~cm}$ ) samples made of concrete of frost resistance grade F270 and class B25 were conducted. At the age of more than 180 days, ultrasonic calibration of the samples followed by cyclic freezing to minus $(42 \pm 2)^{\circ} \mathrm{C}$ and thawing in water at a temperature of $(18 \pm 2)^{\circ}$ $\mathrm{C}$ was conducted. After the planned number of cycles, the samples were tested for axial compression and cleavage in thawed and frozen states. The thermal insulation used in this case made it possible to neglect the temperature change of the cooled concrete during the test. The number of simultaneously tested samples was $12 \div 18$ pieces, depending on the spread of the experimental values.

The prisms were getting loaded continuously with a deformation rate of $0.05 \mathrm{~mm} / \mathrm{min}$, which made it possible to obtain an adequate reaction of concrete at the appropriate level of force impact. Simultaneously, in the automatic mode, the deformation diagram was recorded until the moment of complete physical destruction. Periodicity of tests was adopted taking into account the specificity of frost modification of the structure as an initial compaction process with the subsequent formation and accumulation of microcracks [2]. Stress levels $(\sigma b / R b)$ are used as boundaries of micro-fractures in concrete, at which the maximum value of the ultrasonic wave velocity ( $R_{T}^{0}$ ) and their reduction to the initial (beginning) value is observed.

\section{Results and discussion}

Tables 1-4 give independent statistics of probability distribution models asymptotically acceptable with experimental data, obtained by the maximum likelihood method $[7,8]$. In this case, the consistency of the empirical and theoretical distributions was estimated by the Pearson criterion $(\chi 2)$, which allows minimizing risks from uncertainty in acceptance of the general distribution hypothesis [9].

It is established that in the process of frost destruction of concrete, there is a gradual nonunidirectional change in the density and character of the distribution of all the analyzed indicators of its quality. The normal Gaussian distribution is most consistent with the experimental samples at the stages of $T$ - $W$ impact that do not exceed $70 \div 80 \%$ of standard frost resistance potential. In the future, its reliability is commensurable with the probability of compositional, Laplace-Charlier and other asymmetric distributions. Moreover, this is typical for concrete of thawed and cryogenic states. A more detailed discussion of this question is beyond the scope of this paper, but the observed statistical regularities are taken into account in the following analysis.

For the purposes of this study, the reliability index $[10,11]$ is used as an integral criterion for sensitivity of structure to low-temperature impact, which is equivalent to the probability of its destruction due to cumulative failure when the limit values are reached by corresponding controlled indicators. With normal distribution of the effect of impact and 
considered parameter and their interindependence, the current reliability index is determined by ratio of the average and standard deviation. Taking into account the above transformation of the character of approximating distribution, such a ratio is considered as the first approximation of the value of reliability index at the corresponding stage of the test [10]. Regarding the maximum permissible values of $\beta_{u l t}$, essentially, its magnitude is predetermined by the level of acceptable risk of reaching the corresponding limit state [11] based on social, economic and other criteria of their consequences. Taking into account specifics of the considered impacts and probable failures of cumulative type, $\beta_{u l t}$ can be set at the level of design security of calculated parameters of resistance. It is accepted (by default!) at no less than $99.73 \%$, which corresponds to the value $\beta \approx 3.0$ under the assumption of a normal distribution of the parameter.

In this setting, the index $\beta$ can be considered as an indicator of the design reliability resource, which judging from the experimental data (Tables 1 to 4), significantly differs depending on choice of the criterial parameter of the used dynamic model. In this case, not only the initial value $\beta_{(0)}$ is of fundamental importance, but also its change in the process of frost destruction of concrete and reinforced concrete. If, for the projected expected intensity and magnitude of climatic impact, we take the number of cycles of freezing and thawing equivalent to the frost resistance mark, then by the time of its achievement, reliability of reinforced concrete elements for rigidity and strength of the compressed zone reduces below the permissible level.

The dependence of reliability index on the level of realization of the frost-resistance potential of concrete can also be clearly seen in the kinetics of changes in the fracture toughness of concrete (Fig. 1). Based on tests, a continuous increase in the stress level corresponding to the lower limit $R_{T}^{0}$ occurs. That is, fatigue changes (residual deformations) contribute to the formation of more dense structures of concrete with increased capacity for elastic deformation.

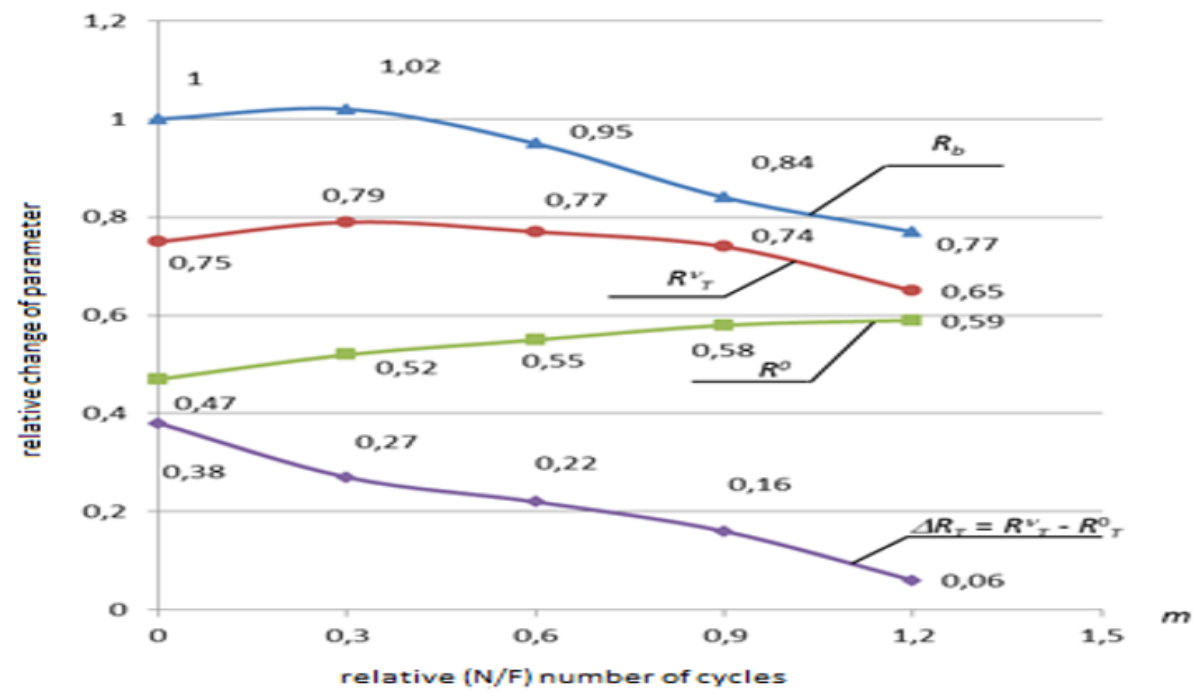

Fig. 1. Kinetics of prismatic strength and fracture boundaries of concrete.

The extremality of changes in $R_{b}(m)$ and $R_{T}^{v}(m)$ indicate the transient nature of the impact of frost destruction of concrete. In the early stages of exposure $(\mathrm{m} \leq 0.3 \div 0.4)$, a positive effect predominates, which can be explained by: 
- reduction of compressive intra-structural forces due to formation of local fatigue cracks [12];

- additional hydration of cement during the period of water storage of samples [13];

- partial replacement of weak point structural bonds by secondary, adhesion-cohesive promoting compacting of concrete [3].

With further impact, the destructive effect of fatigue changes begins to prevail leading to a decrease in the ability of concrete to plastic shear deformations without formation of new fracture surfaces. This is evidenced by an accelerated decrease in the range $R_{T}^{0}-R_{T}^{v}$, which indirectly confirms the megastability of the process of crack development and the reduction of the "conditional path for the development of cracks from the microcrack of the bond zone to the network of continuous fractures" [14]. With this state of concrete structure, the lower boundary $R_{T}^{0}$ loses its meaning as the boundary of elastic deformation under short-term loading and is transformed into the indicator $R_{c r}$ - the level of stresses of secondary decompression [15].

If we take into account that a stress state of this type is identical to the exhaustion of longterm strength of concrete, then the equivalent number of cycles of $T$ - $W$ impact that causes its formation can be regarded as the maximum permissible by the criterion of probable cumulative failure of reinforced concrete elements due to sudden brittle fracture of concrete.

\section{Conclusion}

Project support for the reliability of reinforced concrete elements for a design life in severe climatic conditions can be achieved by considering dynamic models that take into account the statistical patterns of changes in the FTC for all significant indicators of strength and deformation properties of concrete. At the same time, the necessary service life (reserve) of operational fitness can be achieved by calibrating the reliability index $\beta$ to the most sensitive to the FTC controlling parameter in the dynamic model of design situation at hand (limit state).

Table 1. Kinetics of prismatic strength.

\begin{tabular}{|c|c|c|c|c|c|c|}
\hline \multirow[b]{2}{*}{ State } & \multirow[b]{2}{*}{$\begin{array}{l}\text { Number } \\
\text { of cycles }\end{array}$} & \multicolumn{3}{|c|}{ Distribution parameters } & \multirow{2}{*}{$\begin{array}{l}\text { Index of } \\
\text { reliability } \\
\beta=R_{b} / \sigma_{b}\end{array}$} & \multirow[b]{2}{*}{$\beta_{n} / \beta_{0}$} \\
\hline & & $\begin{array}{l}\text { Average } \\
\bar{R}_{b}, \mathrm{MPa}\end{array}$ & $\begin{array}{c}\text { Deviation* } \\
\sigma_{b}, \mathrm{MPa}\end{array}$ & $\begin{array}{l}\text { Variabilit } \\
\text { y } C_{v}, \%\end{array}$ & & \\
\hline Initial & 0 & 24,0 & 3,02 & 12,5 & 7,95 & 1,00 \\
\hline \multirow{3}{*}{ Freezing } & 4 & 33,4 & 3,71 & 11,1 & 9,00 & 1,21 \\
\hline & 30 & 22,4 & 3,41 & 15,2 & 6,57 & 0,83 \\
\hline & 45 & 21,0 & 4,37 & 20,8 & 4,80 & 0,6 \\
\hline \multirow{3}{*}{ Thawing } & 10 & 24,5 & 3,48 & 14,2 & 7,04 & 0,88 \\
\hline & 31 & 20,2 & 5,45 & 27,0 & 3,70 & 0,47 \\
\hline & 45 & 19,1 & 5,1 & 27,0 & 3,74 & 0,46 \\
\hline
\end{tabular}

* - standard deviation.

Table 2. Kinetics of tensile strength of concrete.

\begin{tabular}{|c|c|c|c|c|c|}
\hline \multirow[b]{2}{*}{$\begin{array}{c}\text { Number of } \\
\text { cycles }\end{array}$} & \multicolumn{3}{|c|}{ Distribution parameters } & \multirow[b]{2}{*}{$\begin{array}{c}\text { Index of } \\
\text { reliability } \\
\beta=R_{b t} / \sigma_{b t}\end{array}$} & \multirow[b]{2}{*}{$\beta_{n} / \beta_{0}$} \\
\hline & $\begin{array}{l}\text { Average } \\
\bar{R}_{b t}, \mathrm{MPa}\end{array}$ & $\begin{array}{c}\text { Deviation * } \\
\sigma_{b t}, \mathrm{MPa}\end{array}$ & $\underset{\%}{\text { Variability } C_{v}}$ & & \\
\hline 0 & 3,52 & 0,72 & 20,3 & 4,89 & 1,0 \\
\hline 10 & 3,17 & 0,60 & 18,8 & 5,31 & 1,09 \\
\hline 20 & 2,83 & 0,62 & 22,0 & 4,56 & 0,93 \\
\hline
\end{tabular}




\begin{tabular}{|l|l|l|l|l|l|}
\hline 30 & 1,94 & 0,49 & 24,8 & 3,96 & 0,81 \\
\hline 40 & 1,01 & 0,37 & 36,8 & 2,73 & 0,56 \\
\hline
\end{tabular}

Table 3. Statistics of the distribution of initial modulus of elasticity.

\begin{tabular}{|c|c|c|c|c|c|}
\hline \multirow[b]{2}{*}{$\begin{array}{c}\text { Number of } \\
\text { cycles }\end{array}$} & \multicolumn{3}{|c|}{ Distribution parameters } & \multirow[b]{2}{*}{$\begin{array}{l}\begin{array}{c}\text { Index of } \\
\text { reliability }\end{array} \\
\beta=\bar{E}_{b} / \sigma_{E}\end{array}$} & \multirow[b]{2}{*}{$\beta_{n} / \beta_{0}$} \\
\hline & $\begin{array}{c}\text { Average } \\
\bar{E}_{b} \times 10^{-4} \\
\mathrm{MPa}\end{array}$ & $\begin{array}{c}\text { Deviation * } \\
\sigma_{E} \times 10^{-4}, \mathrm{MPa}\end{array}$ & $\begin{array}{c}\text { Variability } \mathrm{C}_{\mathrm{v}}, \\
\%\end{array}$ & & \\
\hline 0 & 2,99 & 0,48 & 16,1 & 6,23 & 1,0 \\
\hline 10 & 2,92 & 0,44 & 15,2 & 6,64 & 1,07 \\
\hline 31 & 2,19 & 0,55 & 24,9 & 3,08 & 0,49 \\
\hline 45 & 1,35 & 0,47 & 34,8 & 2,87 & 0,46 \\
\hline
\end{tabular}

Table 4. Statistics of the distribution of limit deformation.

\begin{tabular}{|c|c|c|c|c|c|c|}
\hline \multirow[b]{2}{*}{ State } & \multirow{2}{*}{$\begin{array}{l}\text { Number } \\
\text { of cycles }\end{array}$} & \multicolumn{3}{|c|}{ Distribution parameters } & \multirow{2}{*}{$\begin{array}{l}\text { Index of } \\
\text { reliability } \\
\beta=\varepsilon_{b b} / \sigma_{\varepsilon}\end{array}$} & \multirow[b]{2}{*}{$\beta_{n} / \beta_{0}$} \\
\hline & & $\begin{array}{c}\text { Average } \\
\varepsilon_{b} \times 10^{-4}, \mathrm{MPa}\end{array}$ & $\begin{array}{c}\text { Deviation * } \\
\sigma_{\varepsilon} \times 10^{-4}, \mathrm{MPa}\end{array}$ & $\begin{array}{c}\text { Variability } \\
\mathrm{C}_{v}, \%\end{array}$ & & \\
\hline \multirow{4}{*}{ Thawing } & 0 & 16,92 & 3,35 & 19,6 & 5,05 & 1,0 \\
\hline & 10 & 20,00 & 3,54 & 17,7 & 5,65 & 1,12 \\
\hline & 31 & 33,41 & 9,31 & 28,1 & 3,61 & 0,71 \\
\hline & 45 & 65,71 & 20,9 & 31,9 & 3,14 & 0,62 \\
\hline \multirow{3}{*}{ Freezing } & 4 & 10,26 & 1,88 & 18,3 & 5,46 & 1,08 \\
\hline & 31 & 16,56 & 3,65 & 22,0 & 4,54 & 0,9 \\
\hline & 24,7 & 24,7 & 6,41 & 25,9 & 3,85 & 0,76 \\
\hline
\end{tabular}

\section{References}

1. G. I. Gorchakov, E. A. Guzeev, L. A. Seilanov, Concrete and reinforced concrete, 1, 40-42 (1985)

2. V. M. Moskvin, B. M. Kapkin, B. M. Mazur, A. M. Podvalniy, Resistance of concrete and reinforced concrete at negative temperature (Stroyizdat, Moscow, 1967)

3. B. I. Pinus, V. I. Kurilov, Increase of reliability of reinforced concrete structures in aggressive operating environment (East-Siberian Publishing House, Irkutsk, 1977)

4. F. M. Ivanov, Investigation of frost resistance of concrete. Protection against corrosion of building structures and increase of their durability (Stroyizdat, Moscow, 1969)

5. Recommendations on use of additional information to reduce time of testing for reliability (Gorky branch of VNIIMASH, Gorky, 1974)

6. B. I. Pinus, Ensuring durability of functioning of reinforced concrete structures under low-temperature impact.: dissertation for the degree of Doctor of Technical Sciences: 00.00.00: aproved.11.11.11 (Moscow, 1987)

7. G. Kramer, Mathematical methods of statistics (Mir, Moscow, 1975)

8. GOST 27.201.81. Reliability in technology. Evaluation of reliability indicators with small number of observations using additional information. General provisions (Gosstroyizdat USSR, Moscow, 1982)

9. B. V. Gnedenko, Mathematical methods in theory of reliability (Nauka, Moscow, 1965) 10. H. Gulvanesyan, J.-A. Kalgaro, M. Golicki, Guidance to the Eurocode for designers EN 1990: Fundamentals of structures design (MGSU, Moscow, 2011)

10. GOST R ISO 2394-2016. Construction structures. Basic principles of reliability (Standartinform, Moscow, 2016) 
11. K. V. Mikhailov, New on strength of reinforced concrete (Stroyizdat, Moscow, 1977).

12. A. R. Collins, The distruction of Concrete by Frost Jornal of the Instituute of Civil Engeniering, Vol. 23, No. 1 (1994)

13. V. M. Moskvin, M. M. Kapkin, A. N. Savitsky, V. N. Yarmakovskiy, Concrete for construction in harsh conditions (Stroyizdat, Moscow, 1973)

14. A. A. Gvozdev, New in the design of concrete and reinforced concrete structures. (Stroyizdat, Moscow, 1978) 